\title{
Cardiac function assessed by systolic time intervals after aortocoronary saphenous vein bypass surgery ${ }^{1}$
}

\author{
Harvey Matlof ${ }^{2}$, Herbert N. Hultgren, James F. Pfeifer, and Donald C. Harrison \\ From the Cardiology Divisions of Stanford University School of Medicine \\ and the Veterans Administration Hospital, Palo Alto, California, U.S.A.
}

Systolic time intervals were measured in 33 patients undergoing aortocoronary saphenous vein bypass, before operation and 7 days after operation. Eighteen patients had normal systolic time intervals before operation (group I), and I5 had abnormal preoperative intervals (group II). Group I patients experienced significant shortening of the left ventricular ejection time index from $404 \mathrm{msec}$ to $37 \mathrm{I} \mathrm{msec} \mathrm{postoperatively}(P<0 \cdot 00 \mathrm{I})$, with no significant change in the pre-ejection phase index. These changes are consistent with acute left ventricular dysfunction in the early postoperative period. Group II patients had an entirely different response, with no significant change in the postoperative left ventricular ejection time index and a significant decrease in the pre-ejection phase index from $155 \mathrm{msec}$ to $143 \mathrm{msec}(P<0.001)$. The shortening of pre-ejection phase index may have represented improved ventricular function after operation. An alternative explanation for pre-ejection phase index shortening would be the effects of adrenergic stimulation. Later observations at $I$ to 2 months suggested that the group I response was transient and the group II response was sustained.

During recent years, there has been a resurgence of interest in the surgical approach to coronary artery disease. This has been brought about by the technique of aortocoronary saphenous vein bypass surgery, which has been shown to alleviate angina pectoris in a high percentage of patients (Johnson et al., 1969; Mitchell et al., 1970; Spencer, I970). Though most observers agree that relief of angina is significant, there are less detailed data available on the effect of the operation on left ventricular haemodynamics. Several studies in relatively small groups of patients have shown postoperative improvements in ejection fraction (Rees et al., 1971; Chatterjee et al., 1971; Mailhot, Sandler, and Harrison, 197I), end-systolic volume (Rees et al., 1971), and postexercise left ventricular end-diastolic pressure (Rees et al., I97I; Chatterjee et al., I97I; Johnson et al., 1970; Campeau et al., 197I). In one study by Dorchak et al. (197I), no improvement in ejection fraction was noted in 17 of 18 patients with abnormal preoperative values.

Received 29 January 1973.

1 This work was supported in part by N.I.H. grants, and a grant from the National Aeronautics and Space Administration.

2 Present address: Sutter Memorial Hospital, Sacramento, California 95819, U.S.A.
Most of the aforementioned studies were performed several weeks to months after operation. The purpose of the present study was to assess the early haemodynamic effects of aortocoronary vein bypass surgery in a reasonably large group of patients. Because of its reported reliability and ease of performance, the method of externally measured systolic time intervals (Weissler, Harris, and Schoenfeld, 1968, 1969; Martin et al., 1971; Spodick, Dorr, and Calabrese, 1969) was chosen as the means of comparing pre- and postoperative ventricular function.

\section{Subjects and methods}

Thirty-three patients undergoing aortocoronary vein bypass surgery were evaluated by phonocardiographic measurement of systolic time intervals as described by Weissler et al. (1968). An Elema Scholander 4-channel recorder was used for recording in all patients. All records were made at a paper speed of $100 \mathrm{~mm} / \mathrm{sec}$. The carotid pulse was recorded with a pressure cup via rubber tubing in series with an air-coupled transducer (Hewlett Packard Model 2 I05 I D). The left ventricular ejection time was measured from the onset of the rapid carotid upstroke to the dicrotic notch. Total electromechanical systole, or the $\mathrm{qS}_{2}$ interval, was measured from the onset of the $q$ wave of the electrocardiogram to the onset of the first high frequency vibrations of the 
second heart sound. The pre-ejection phase was derived by subtracting the left ventricular ejection time from the $\mathrm{qS}_{2}$ interval for each individual set of measurements. All intervals represented the average of ro individually measured cardiac cycles.

All patients were studied one day before operation and again at one week after operation. Fifteen patients were restudied one to two months after operation. Most of the patients were studied in the fasting state in the early morning. Where this was not possible, pre- and postoperative studies were done at the same time of day for each patient in order to avoid the minor effects of diurnal variation (Weissler et al., 1965). All patients were in normal sinus rhythm without AV or intraventricular conduction disturbances. Patients receiving digitalis preparations were included only if they were taking the same dose at the time of both measurements.

The 33 patients underwent vein bypass operation on cardiopulmonary bypass. Serial electrocardiograms and serum enzymes were available on all patients.

In order to correct for the effects of heart rate or systolic time intervals, the following equations, derived by Weissler et al. (1968), were used:

I) Left ventricular ejection time index (msec).

$($ LVETI $)=$ measured LVET $+\mathrm{I} \cdot 7 \times \mathrm{HR}($ men $)$

and $=$ measured LVET $+\mathrm{I} \cdot 6 \times \mathrm{HR}$ (women).

2) Pre-ejection phase index (msec).

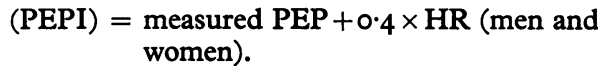

3) PEP/LVET ratio was expressed as the ratio of the two directly measured intervals, uncorrected for heart rate.

\section{General}

\section{Results}

There were 33 patients studied pre- and postoperatively, consisting of 27 men and 6 women. The mean age of the group was 48 years. One death occurred in a 58-year-old woman (Case 8) who died three weeks after operation after sustaining intraoperative and postoperative myocardial infarctions. None of the patients was in obvious congestive heart failure preoperatively, though 6 were on digitalis preparations. Six patients had suspected or proven intraoperative myocardial infarctions (Table). One patient had suspected infarction on the basis of a peak postoperative serum aspartate aminotransferase greater than I00 IU/1. (with upper limit of normal 40 Sigma Frankel/1.) (Hultgren et al., I97I ; Greenberg et al., 1970) without new q waves. Five patients had developed new $q$ waves as well as aspartate aminotransferase values greater than Ioo Sigma Frankel/1. None of the 27 patients with peak postoperative aminotransferase values below Ioo Sigma Frankel/l. had new $\mathrm{q}$ waves in the postoperative cardiograms.

\section{Preoperative systolic time intervals}

The study population was separated into two sub- groups, on the basis of the preoperative pre-ejection phase-left ventricular ejection time ratio (PEP/ LVET). Using a cutoff ratio of 0.43 , there were I8 patients below and 15 patients above this value. The 18 patients with ratios below 0.43 were considered to have essentially normal systolic time intervals and are referred to as group I patients. The 15 with ratios over 0.43 were felt to have $a b$ normal systolic time intervals and are designated group II. The cutoff point of 0.43 was based on studies by Weissler, which indicated that a value of 0.43 would be two standard deviations above a normal population mean of 0.35 (Weissler et al., 1969). The ratio has been shown to have good correlation with directly measured parameters of left ventricular function (Weissler et al., I969; Garrard, Weissler, and Dodge, 1970). The preoperative intervals differed between these two groups (Table). Group I patients had a mean left ventricular ejection time interval of 404, a pre-ejection phase index of 134 , and a PEP/LVET ratio of 0.37 . These values all fall within the normal range described by Weissler et al. (I969). Group II patients had abnormalities of all three parameters, with left ventricular ejection time index of 377 , a pre-ejection phase index of I55, and a PEP/LVET ratio of 0.50 .

Adequate left ventriculograms for calculation of ejection fraction were available for 7 group I and 9 group II patients. Measurements were made using the single plane, area-length method of Sandler and Dodge (1968). The mean ejection fraction for group I was 77.6 per cent $( \pm 7 \cdot 6)$ and for group II was $58 \cdot \mathrm{I}$ per cent $( \pm 9 \cdot 3)$. These values were significantly different $(\mathrm{P}<0.0 \mathrm{I})$. In addition, 8 of the 9 group II studies showed localized abnormalities in left ventricular contraction which were not present in any of the 7 group I ventriculograms. Therefore, the two groups seemed separable on the basis of invasive studies, as well as the preoperative systolic time intervals.

\section{Postoperative changes}

The two groups were not only different in their initial values, but seemed to differ in their early systolic time interval response to operation (Table and Fig. I-3). Group I patients showed a shortening of left ventricular ejection time index from 404 preoperatively to $37 \mathrm{I} \mathrm{msec}$ postoperatively ( $\mathbf{P}<0.001)$. The group II patients sustained a statistically insignificant drop in the index from 377 to 37 I msec (Fig. I). The pre-ejection phase index in group I was unaltered, with pre- and postoperative values of 134 and $133 \mathrm{msec}$, respectively (Fig. 2). Group II patients, on the other hand, underwent a shortening of the pre-ejection phase index from 
TABLE Pre- and postoperative systolic time intervals, heart rate, and serum aspartate aminotransferase (SGOT)

\begin{tabular}{|c|c|c|c|c|c|c|c|c|c|c|c|}
\hline \multirow{2}{*}{$\begin{array}{l}\text { Case } \\
\text { No. } \\
\text { Group }\end{array}$} & \multirow{2}{*}{$\begin{array}{l}\text { Age } \\
(y r) \\
I\end{array}$} & \multirow[t]{2}{*}{ Sex } & \multicolumn{2}{|c|}{ LVETI (msec) } & \multicolumn{2}{|c|}{$P E P I$ (msec) } & \multicolumn{2}{|c|}{$P E P / L V E T$} & \multirow{4}{*}{$\begin{array}{l}\text { Peak } \\
\text { SGOT } \\
\text { Postop. } \\
71 \\
240^{\star}\end{array}$} & \multicolumn{2}{|c|}{ Heart rate } \\
\hline & & & Preop. & Postop. & Preop. & Postop. & Preop. & Postop. & & Preop. & Postop. \\
\hline I & 55 & $\mathbf{M}$ & 396 & 366 & 139 & 145 & 0.39 & 0.54 & & 74 & 100 \\
\hline 2 & 53 & $\mathbf{M}$ & 433 & 372 & 138 & 125 & 0.34 & 0.37 & & 45 & 69 \\
\hline 3 & 65 & F & 424 & 373 & 140 & 146 & 0.32 & 0.45 & $3 I$ & 56 & 70 \\
\hline 4 & 47 & M & 425 & 381 & 135 & 125 & 0.35 & $0.4 I$ & 36 & 63 & 80 \\
\hline 5 & 39 & $F$ & 381 & 368 & 136 & 151 & 0.39 & 0.52 & 60 & 56 & 91 \\
\hline 6 & 55 & $\mathbf{M}$ & 419 & 374 & 125 & I5I & 0.32 & 0.51 & 25 & 62 & 86 \\
\hline 7 & 55 & $\mathbf{M}$ & 409 & 373 & 134 & 136 & $0 \cdot 38$ & 0.45 & 33 & 70 & 88 \\
\hline 8 & 58 & $F$ & 402 & 34I & 138 & 140 & 0.38 & 0.50 & $512^{\star}$ & 69 & 76 \\
\hline 9 & 36 & $M$ & 422 & 373 & I44 & 109 & 0.39 & 0.33 & 36 & 78 & 88 \\
\hline I0 & 54 & $\mathbf{M}$ & 418 & 371 & I3I & I4I & 0.33 & 0.47 & 70 & 57 & 76 \\
\hline I I & 49 & $\mathbf{M}$ & 388 & 372 & 113 & II8 & 0.31 & 0.39 & $226^{\star}$ & 60 & 72 \\
\hline 12 & 49 & $M$ & 396 & 367 & 128 & 128 & 0.35 & 0.39 & 34 & $6 I$ & 65 \\
\hline 13 & 42 & $\mathbf{M}$ & 366 & 372 & 124 & 130 & 0.38 & 0.42 & 70 & 55 & 86 \\
\hline 14 & 47 & $\mathbf{M}$ & 401 & 364 & 147 & 135 & $0.4 \mathrm{I}$ & 0.47 & 52 & 62 & 88 \\
\hline 15 & 42 & M & 394 & 385 & I39 & 129 & $0.4 I$ & $0.4 \mathrm{I}$ & $152^{\star}$ & 73 & 97 \\
\hline 16 & 34 & M & 414 & 370 & 132 & 140 & 0.36 & 0.50 & 60 & 79 & 100 \\
\hline I7 & 60 & M & 387 & $36 I$ & 144 & II8 & 0.42 & 0.38 & 42 & 60 & 71 \\
\hline 18 & 52 & $\mathbf{M}$ & 404 & 379 & 132 & 132 & 0.37 & 0.42 & $3 I$ & 79 & 82 \\
\hline \multicolumn{3}{|c|}{ Mean $\pm($ SEM $)$} & $\begin{array}{l}404 \\
( \pm 4)\end{array}$ & $\begin{array}{l}371 \\
( \pm 2) \\
P<0.001\end{array}$ & $\begin{array}{l}134 \\
( \pm 2)\end{array}$ & $\begin{array}{l}133 \\
( \pm 3) \\
P=N S\end{array}$ & $\begin{array}{l}0.37 \\
( \pm 0.01)\end{array}$ & $\begin{array}{l}0.44 \\
( \pm 0.01) \\
P<0.001\end{array}$ & & $\begin{array}{c}64 \\
( \pm 2)\end{array}$ & $\begin{array}{l}84 \\
( \pm 3) \\
P<0 \cdot 01\end{array}$ \\
\hline \multicolumn{12}{|c|}{ Group II } \\
\hline 19 & 50 & $\mathbf{M}$ & 383 & 350 & 165 & 138 & 0.52 & 0.41 & 30 & 67 & 9I \\
\hline 20 & 59 & $\mathbf{M}$ & 378 & 354 & 139 & 127 & 0.43 & 0.42 & rigt & 67 & 68 \\
\hline 21 & 48 & $\mathbf{M}$ & 388 & 390 & 155 & 150 & 0.48 & 0.48 & 27 & 77 & 92 \\
\hline 22 & 48 & $\mathbf{M}$ & 384 & 379 & 145 & I50 & 0.43 & 0.48 & 59 & 6I & 76 \\
\hline 23 & 50 & $M$ & 374 & 377 & 157 & 148 & 0.46 & 0.46 & 38 & 67 & 69 \\
\hline 24 & 49 & $\mathbf{M}$ & 380 & 354 & 160 & 162 & 0.57 & 0.52 & 44 & 100 & 79 \\
\hline 25 & 45 & $\mathbf{M}$ & 390 & 378 & 145 & 142 & 0.46 & 0.47 & 44 & 88 & 90 \\
\hline 26 & 58 & $\mathbf{M}$ & 389 & 375 & 160 & 136 & 0.49 & 0.46 & 70 & 70 & 9I \\
\hline 27 & 52 & $\mathbf{M}$ & 384 & 402 & 159 & I43 & 0.51 & 0.42 & 62 & 79 & 79 \\
\hline 28 & 26 & $\mathrm{~F}$ & $38 \mathrm{I}$ & 381 & 147 & 124 & 0.45 & 0.37 & 64 & 62 & 95 \\
\hline 29 & 44 & $\mathbf{M}$ & 359 & 364 & 158 & 145 & 0.55 & 0.52 & 50 & 72 & 98 \\
\hline 30 & 52 & $M$ & 360 & 345 & 138 & 135 & 0.46 & 0.52 & 190 & 71 & 91 \\
\hline 31 & 50 & $\mathbf{M}$ & 372 & 375 & 174 & 144 & 0.56 & 0.48 & 29 & 60 & 85 \\
\hline 32 & 45 & $\mathbf{M}$ & 397 & 371 & 155 & I4I & 0.45 & 0.50 & NÁ & 63 & 71 \\
\hline 33 & 60 & $\mathbf{M}$ & $34 \mathrm{I}$ & 332 & 163 & 160 & 0.65 & 0.63 & 56 & 83 & 82 \\
\hline \multicolumn{3}{|c|}{ Mean $\pm($ SEM $)$} & $\begin{array}{l}377 \\
( \pm 4)\end{array}$ & $\begin{array}{l}37 \mathrm{I} \\
( \pm 5) \\
\mathrm{P}=\mathrm{NS}\end{array}$ & $\begin{array}{l}155 \\
( \pm 3)\end{array}$ & $\begin{array}{l}I 43 \\
( \pm 3) \\
P<0.001\end{array}$ & $\begin{array}{l}0.50 \\
( \pm 0.02)\end{array}$ & $\begin{array}{l}0.48 \\
( \pm 0.02) \\
P=N S\end{array}$ & & $\begin{array}{c}74 \\
( \pm 3)\end{array}$ & $\begin{array}{l}83 \\
( \pm 2) \\
P<0.05\end{array}$ \\
\hline
\end{tabular}

$\star$ Peak postoperative serum aspartate aminotransferase $>100$ IU/1., with electrocardiographic evidence of acute infarction.

$\dagger$ Peak postoperative serum aspartate aminotransferase $>100$ IU/1., without electrocardiographic evidence of acute infarction. LVETI = left ventricular ejection time index; PEPI = pre-ejection phase index.

I55 to $143 \mathrm{msec}(P<0.00 \mathrm{I})$. Thirteen of the 15 patients in group II demonstrated a shortened preejection phase index postoperatively. The PEP/ LVET ratio in group I rose significantly from 0.37 to $0.44(\mathrm{P}<0.001)$. The group II response again differed by dropping slightly from 0.50 to 0.48 (Fig. 3). This change was not statistically significant.

Six patients were suspected of sustaining intraoperative myocardial infarction on the basis of postoperative serum aspartate aminotransferase values exceeding I00 IU/1. (Hultgren et al., I97I; Greenberg et al., 1970). The left ventricular ejection time index in this group decreased from 392 to 362 postoperatively. The pre-ejection phase index went from 134 to 129 , and the PEP/LVET ratio from 0.39 to 0.44 . These responses are similar to that of the group I patients.

Group I patients with normal preoperative systolic time intervals showed abnormal systolic time intervals postoperatively consisting of significant shortening of the left ventricular ejection time index, a rise in the PEP/LVET ratio, and no change in the pre-ejection phase index. Group II patients had a very different response, including a shortened pre- 


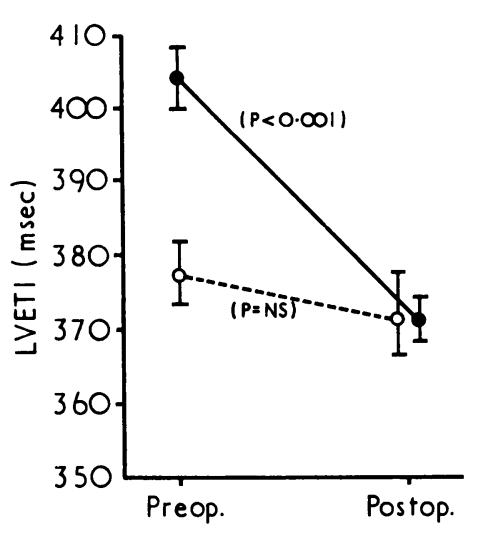

FIG. I.
FIG. 2.

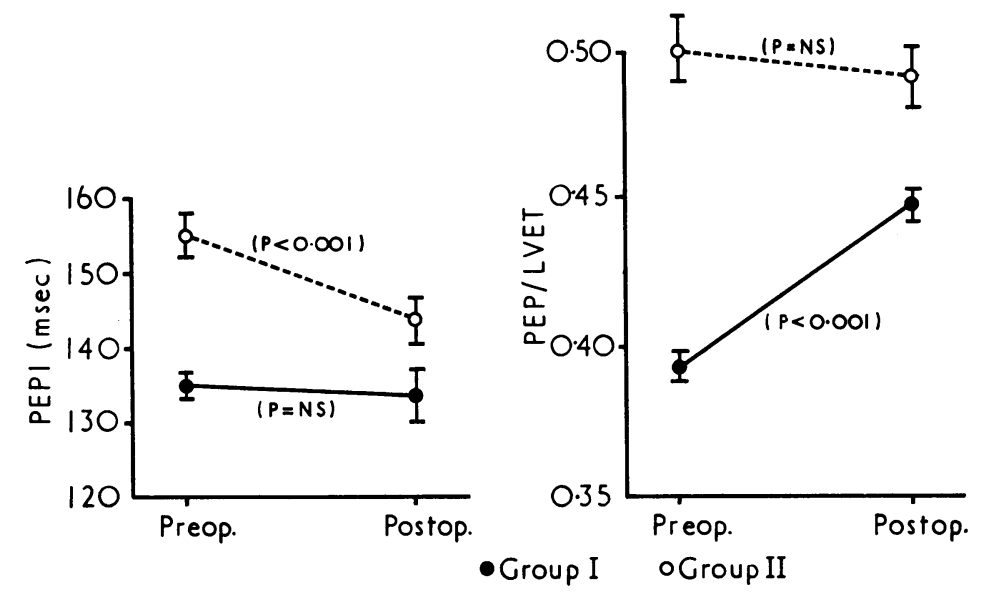

Fig. 3.

FIG. I Left ventricular ejection time index (LVETI) before and 7 days after operation.

FIG. 2 Pre-ejection phase index (PEPI) before and 7 days after operation.

FIG. 3 PEP/LVET ratio before and 7 days after operation.

ejection phase index without significant change in left ventricular ejection time index or PEP/LVET ratios.

\section{Discussion}

The 18 group I patients with normal preoperative systolic time intervals had evidence of acute left ventricular dysfunction postoperatively, as evidenced by significant shortening of the left ventricular ejection time index and increase in the PEP/LVET ratio, without change in the pre-ejection phase index. These types of changes are identical to previously reported effects of acute myocardial infarction on systolic time intervals (Toutouzas et al., 1969; Heikkila, Luomanmaki, and Pyorala, 197I; Jain and Lindahl, 1971). They differ from intervals noted in patients with chronic heart failure, in whom a lengthened pre-ejection phase has been reported, in addition to a shortened left ventricular ejection time (Weissler et al., 1968; Garrard et al., 1970).

The pre-ejection phase comprises isovolumic contraction time and the electromechanical delay. The isovolumic contraction time lengthens when chronic myocardial dysfunction is present (Weissler et al., I968) and shortens under the influence of catecholamines (Harris et al., 1966). Since patients with acute left ventricular dysfunction (e.g. myocardial infarction) are in a state of adrenergic stimulation (Valori, Thomas, and Shillingford, 1967), the opposing effects result in little or no net effect on the pre-ejection phase (Toutouzas et al., 1969; Heikkila et al., I97I ; Jain and Lindahl, I97I). The left ventricular ejection time index shortening probably reflects a drop in stroke volume (Heikkila et al., I97I).
The decrease in left ventricular ejection time index in group I patients could theoretically be due entirely to an enhanced systolic ejection rate induced by catecholamine secretion in the early postoperative period. If one assumes this and rejects the hypothesis of acute lowering of stroke volume, then one would expect that the pre-ejection phase index would be shortened rather than remain unchanged for the group. Harris and co-workers have shown that adrenaline or isoprenaline infusion results in a shortening of both the pre-ejection phase and left ventricular ejection time (Harris et al., 1966). Furthermore, the pre-ejection phase shortening was relatively greater than left ventricular ejection time shortening. Thus, if one calculates the pre- and post-cathecholamine infusion PEP/LVET ratios from Harris's study, there was a decrease rather than the increase noted in our group I patients postoperatively.

Another argument favouring acute myocardial dysfunction in group $I$ is that their postoperative changes were the same as the 6 patients who had suspected or documented intraoperative myocardial infarctions.

The acute alterations in left ventricular ejection time intervals in group I were transient. Ten of these patients were available for restudy one to two months postoperatively. Fig. 4 shows that the left ventricular ejection time index in all of these patients returned to normal values of $400 \mathrm{msec}$ or greater.

One would not expect the group I patients to have improved systolic time intervals postoperatively, since they already had evidence for normal left ventricular function preoperatively. We feel that the 


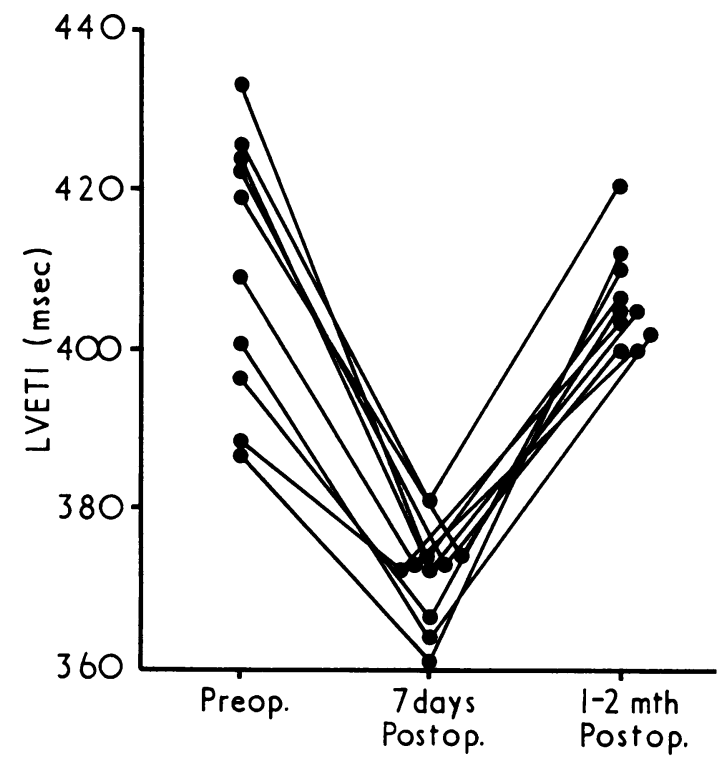

FIG. 4 Left ventricular ejection time index (LVETI) in 10 group I patients, measured 7 days before, and $I$ to 2 months after operation.

acute, transient depression of systolic time intervals observed in these patients reflects the acute deleterious effects of cardiopulmonary bypass, as well as the temporary coronary inflow occlusion required during the time necessary for anastomosing the saphenous vein to the distal coronary artery (Kirklin and Rastelli, 1967; Greenberg and Edmunds, 196r ; Stoney and Roe, 1964).

Group II patients had evidence for chronic myocardial dysfunction preoperatively on the basis of abnormal systolic time intervals with a short left ven- tricular ejection time index, long pre-ejection phase index, long and high PEP/LVET ratio (Weissler et al., 1968; Garrard et al., 1970). Postoperatively their changes in systolic time intervals differed from those of group I. There was no significant change in left ventricular ejection time index or PEP/LVET ratio, but there was a significant shortening of the preejection phase index. There was no parameter which indicated the acute depression seen in group I patients, and indeed, the shortened pre-ejection phase index could be interpreted as showing improved left ventricular performance with a more rapid isovolumic contraction time (Weissler et al., 1968, 1969). An alternative explanation would be that there was no net postoperative effect on ventricular performance, and that the shortened preejection phase index reflected the effects of endogenous catecholamine stimulation (Harris et al., I966).

Although both groups of patients were exposed to the same surgical procedures, they differed in their systolic time interval response after operation. This might be interpreted as suggesting that the improved coronary blood flow achieved in group II improved myocardial function enough to offset the deleterious effects of operation, whereas the group I patients, with normal preoperative systolic time intervals, showed the deleterious effects only.

In order further to substantiate improvements in group II patients, it would have been helpful to have later measurements of systolic time intervals at a time when the acute effects of operation were no longer present. Unfortunately, only 5 of these patients were available for restudy, one to two months after operation. Of the 5 patients, 4 experienced lengthening of the left ventricular ejection time index, a shortened pre-ejection phase index,
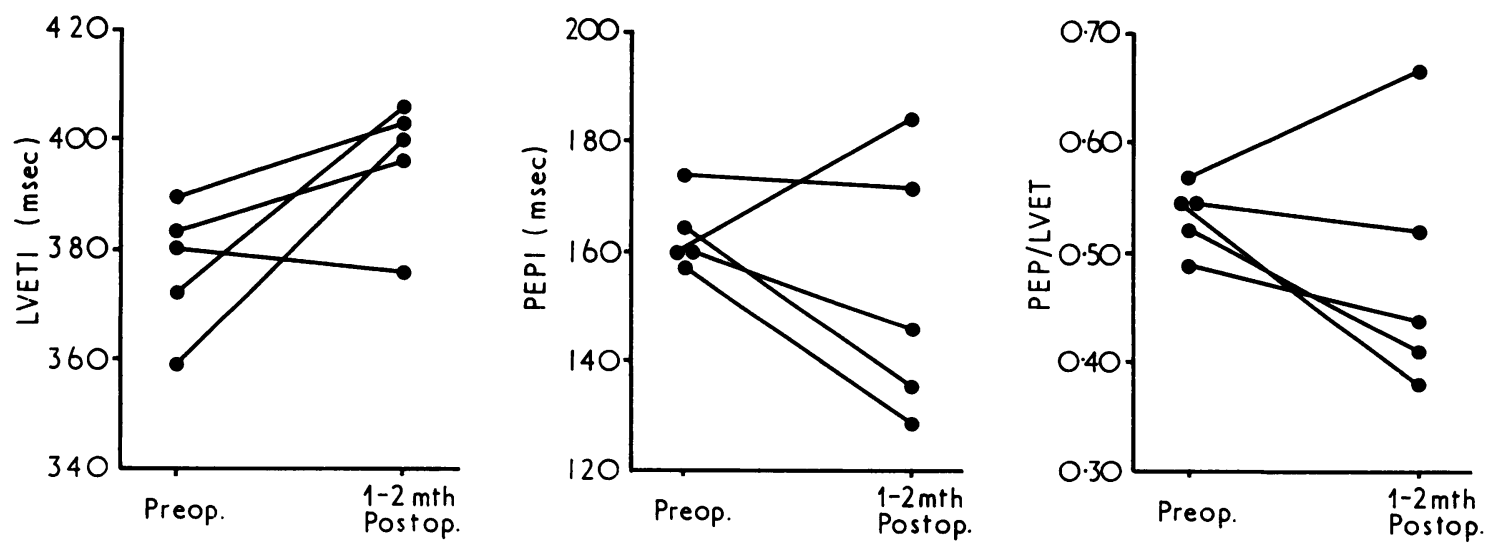

FIG. 5 Left ventricular ejection time index, pre-ejection phase index, and PEP/LVET ratio in 5 group II patients, measured before and I to 2 months after operation. 
and a lowered PEP/LVET ratio (Fig. 5). Though the number of observations is small, there is a suggestion of haemodynamic improvement reflected in these values. These late changes are very similar to the results of Johnson and O'Rourke who studied a group of ro patients with abnormal preoperative systolic time intervals (Johnson and O'Rourke, 197I). These patients had improved intervals one month after operation.

In summary, these data suggest that patients with angina and abnormal systolic time intervals experience some improvement in systolic time intervals after aortocoronary saphenous vein bypass, which is detectable in the early postoperative period. This has also been suggested in several other studies performed several weeks after operation using invasive techniques (Rees et al., 1971; Chatterjee et al., 1971; Mailhot et al., 1971; Johnson et al., 1970; Campeau et al., 1971).

Another aspect of the present study is that patients with normal preoperative systolic time intervals show evidence for depressed myocardial function transiently in the early postoperative period.

\section{References}

Campeau, L., Alonzo, F., Elias, G., and Bourassa, M. G. (197I). Left ventricular performance during exercise before and after aortocoronary vein graft surgery (abstract). Circulation, 44, Suppl. II, I48.

Chatterjee, K., Marcus, H., Blum, R., Parmley, W., Swan, H. J. C., and Matloff, J. (I97I). Left ventricular function following aortocoronary bypass (abstract). Circulation, 44, Suppl. II, 150.

Dorchak, J. R., Tristani, F. E., Chaing, L. C., and Youker, J. E. (I97I). Left ventricular performance following saphenous vein bypass surgery (abstract). Circulation, 44, Suppl. II, 159.

Garrard, C. L., Weissler, A. M., and Dodge, H. T. (1970). Relationship of alterations in systolic time intervals to ejection fraction in patients with cardiac disease. Circulation, 42, 455 .

Greenberg, B. H., McCallister, B. D., Frye, R. L. and Wallace, R. B. (1970). Serum glutamic oxaloacetic transaminase and electrocardiographic changes after myocardial revascularization procedures in patients with coronary artery disease. American fournal of Cardiology, 26, 135.

Greenberg, J. J., and Edmunds, L. H. (196I). Effect of myocardial ischemia at varying temperatures on left ventricular function and tissue oxygen tension. Fournal of Thoracic and Cardiovascular Surgery, 42, 84.

Harris, W. S., Schoenfeld, C. D., Brooks, R. H., and Weissler, A. M. (1966). Effect of beta-adrenergic blockade on the hemodynamic responses to epinephrine in man. American Fournal of Cardiology, 17, 484.

Heikkila, J., Luomanmaki, K., and Pyorala, K. (I97I). Serial observations on left ventricular dysfunction in acute myocardial infarction. II. Systolic time intervals in power failure. Circulation, 44, 343.

Hultgren, H. N., Miyagawa, M., Buck, W., and Angell, W. W. (1971). Ischemic myocardial injury during coronary artery surgery. American Heart fournal, 82, 624.

Jain, S. R., and Lindahl, J. (197I). Apex cardiogram and systolic time intervals in acute myocardial infarction British Heart fournal, 33, 578.
Johnson, A., and O'Rourke, R. (1971). Effect of myocardial revascularization on systolic time intervals in patients with left ventricular dysfunction (abstract). Circulation, 44, Suppl. II, I03.

Johnson, W. D., Flemma, R. J., Lepley, D., and Ellison, E. H. (1969). Extended treatment of severe coronary artery disease; a total surgical approach. Annals of Surgery, 170, 460.

Johnson, W. D., Flemma, R. J., Manley, J. C., and Lepley, D. (1970). The physiologic parameters of ventricular function as affected by direct coronary surgery. Fournal of Thoracic and Cardiovascular Surgery, 60, 483.

Kirklin, J. W., and Rastelli, G. C. (1967). Low cardiac output after open intracardiac operations. Progress in Cardiovascular Diseases, 10, 117.

Mailhot, J., Sandler, H., and Harrison, D. C. (1971). Left ventricular function following coronary bypass surgery, Circulation, 44, Suppl. II, I96.

Martin, C. E., Shaver, J. A., Thompson, M. E., Reddy, P. S.. and Leonard, J. J. (I97I). Direct correlation of external systolic time intervals with internal indices of left ventricular function in man. Circulation, 44, 419.

Mitchell, B. F., Adam, M., Lambert, C. J., Sungu, U., and Shiekh, S. (1970). Ascending aorta-to-coronary artery saphenous vein bypass grafts. Fournal of Thoracic and Cardiovascular Surgery, 60, 457.

Rees, G., Bristow, J. D., Kremkau, E. L., Green, G. S., Herr, R. H., Griswold, H. E., and Starr, A. (1971). Influence of aortocoronary bypass surgery on left ventricular performance. New England Fournal of Medicine, 284, 1116.

Sandler, H., and Dodge, H. T. (1968). The use of single plane angiocardiograms for the calculation of left ventricular volume in man. American Heart fournal, 75, 325.

Spencer, F. C. (1970). Venous bypass grafts for occlusive disease of the coronary arteries. American Heart fournal, 79, 568.

Spodick, D. H., Dorr, C. A., and Calabrese, B. F. (1969). Detection of cardiac abnormality by clinical measurement of left ventricular ejection time: A prospective study of 200 unselected patients. Fournal of the American Medical Association, 209, 239.

Stoney, R. J., and Roe, B. B. (1964). Ventricular function after induced intermittently ischemic ventricular fibrillation: effect of moderate hypothermia. Fournal of Thoracic and Cardiovascular Surgery, 48, 838.

Toutouzas, P., Gupta, D., Samson, R., and Shillingford, J. (1969). Q- second sound interval in acute myocardial infarction. British Heart fournal, 31, 462.

Valori, C., Thomas, M., and Shillingford, J. (1967). Free noradrenaline and adrenaline excretion in relation to clinical syndromes following myocardial infarction. American fournal of Cardiology, 20, 605.

Weissler, A. M., Harris, W. S., and Schoenfeld, C. D. (1968). Systolic time intervals in heart failure in man. Circulation, 37, 149.

Weissler, A. M., Harris, W. S., and Schoenfeld, C. D. (1969). Bedside technics for the evaluation of ventricular function in man. American fournal of Cardiology, 23, 577.

Weissler, A. M., Kamen, A. R., Bornstein, R. S., Schoenfeld. C. D., and Cohen, S. (1965). Effect of Deslanoside on the duration of the phases of ventricular systole in man, American fournal of Cardiology, 15, I53.

Requests for reprints to Dr. Donald C. Harrison, Cardiology Division, Stanford University School of Medicine, Stanford, California 94305, U.S.A. 